\title{
How To Do India Is An Enigma: A In-Depth Look Into Indian Workers, Consumers And Its Business Culture
}

\author{
https://doi.org/10.21272/sec.3(2).100-109.2019
}

\section{Rajesh V. Srivastava}

$\mathrm{PhD}$, Associate Professor, Management and Marketing Department, Jennings A. Jones College of Business, Middle Tennessee State University, USA

\begin{abstract}
India is making a transition from an underdeveloped country to a fast developing country. The economy has taken off in last 20 years and GDP growth has averaged over $7 \%$ in last ten years. It is expected to have the third biggest economy by 2035. Currently it is world's fourth largest economy, behind only US, China and European Union. India is still a mixed economy with half of its workers depend on agricultural. However, the government of India has started to stress on manufacturing while still continuing to do very well in outsourcing and a cheap source of imports. It has a low cost of living, and continues to have a strong English speaking educated work force. It has a populations of 1.3 billion people who come from very diverse background. It is also a middle class of 250 million people, making it a very attractive consumer market. $64 \%$ of India's population is under 25 years of age, making it one of the youngest population in the world.

India, like many other developing countries, is facing many challenges (Aarati and Lokeshwarri 2015). In the recent past, U.S. monetary policy has affected India's economy. When the Federal Reserve began its quantitative easing program, the lower interest rates strengthened the value of the dollar. This caused the value of India's rupee to fall to almost $70 \mathrm{RS}$ to USD. The resulting 9.6 percent inflation forced India's central bank to raise its interest rates. US has recently become India's key ally. India's foreign exchange has to US \$400 billion.
\end{abstract}

India's GDP is expected to reach US \$ 6 Trillion and its consumption triple to US \$ 3 trillion by 2025 making it one of the most attractive destination for business.

Keywords: consumer market, culture, developing country, India, labor force, workforce.

JEL Classification: M0.

Cite as: Srivastava, Rajesh V. (2019). How To Do India Is An Enigma: A In-Depth Look Into Indian Workers, Consumers And Its Business Culture. SocioEconomic Challenges, 3(2), 100-109.

https://doi.org/10.21272/sec.3(2).100-109.2019.

(C) The Author, 2019. This article is published with open access at Sumy State University.

\section{Introduction}

"So far as I am able to judge, nothing has been left undone, either by man or nature, to make India the most extraordinary country that the sun visits on his rounds. Nothing seems to have been forgotten, nothing overlooked." "India is the cradle of the human race, the birthplace of human speech, the mother of history, the grandmother of legend, and the great grand mother of tradition. Our most valuable and most astrictive materials in the history of man are treasured up in India only!" - Mark Twain.

"India is fast becoming one of the world's software superpowers." And "In a few years India's economy will be larger than the United States." - Bill Clinton, former president of the United States. "The key is the quality of the human talent here. When people do software projects in India, they do so because this is the place they can find people with latest skills. It is not on the (cheap) price (of labor)." Said Bill Gates when he announced the $\$ 50$ million expansion plan for his Microsoft Corporation's development center in the southern city of Hyderabad. He said this "country was fast becoming a software superpower."

India as a superpower is a relatively new concept but the country's potential for greatness is not. While business leaders and moneymakers are noticing her rather unreal growth in the last decade, brilliant people always acknowledged her over the centuries. With a history that can be traced back more than two millennia 
BC, India saw the beginning of many things. Albert Einstein credited India with teaching the world to count. Will Durant, American historian, called India our mother while crediting the country for giving us our language, our philosophy, our math, our Christian ideals (through the Buddha), self-government and democracy. While superpowers have come and gone over the vast years of our existence, India has stood quietly by. Now India has something to say. Since its declared independence from Britain in 1947, the country has grown increasingly stronger on our global scale. However slowly this progression has been over the last half century, the last decade of Indian advancements has been in superspeed. While an abundance of papers are devoted to China's readiness amazing growth, scholars are slowly realizing that India just might be the country at the finish line. India's progressing democracy is the turtle to China's hare.

India's GDP grew by $7.3 \%$ in the quarter ending in March 2019, which was the fastest growing economy in the world. It is the sixth largest economy in the world but is the third largest economy by Purchasing Power Parity. Perhaps even more impressive fact this that it has world's fastest growing service sector. It also ranks second in the world in farm output. It also has one of the fastest growing e-commerce markets (Wikipedia, 2018).

Today India's technological stand is growing at an astounding rate. Due to increased privatization from liberalization, the Indian competitive edge is rising. The Asian Development Bank has had its eye in India for quite some time with the most noted reasons being a strong industrial sector, a significantly successful software industry, a reform-minded government and services sector that is on the rise. (Hilsenrath 2000, Roy 2016) The country possesses competitive IT talent and is experiencing significant growth, especially in the last two decades. India is the leading outsource destination across the world, accounting for $55 \%$ of the world's $\$ 190$ billion global business (IBEF 2018). India is experiencing explosive growth in the internet industry. It is expected to double to $\$ 250$ billion in 2020 and the number of internet user is expected to reach to 730 million according to National Association of Software and Service Companies (NASSCOM 2018).

In this paper I will first explore the advancements that India is experiencing, along with forecasts for the future. Second, because India is becoming such a force on a worldwide scope, more and more businesses will be dealing with the advancing country. The second half of my paper covers culturally significant information that a Westerner would need to educate himself on before they enter the country. I have also included a list of do's and don'ts while doing business in India.

\section{Cultural Notes}

"In India, I found a race of mortals living upon the Earth, but not adhering to it, inhabiting cities, but not being fixed to them, possessing everything, but possessed by nothing." - Apollonius Tyanaeus, Cappadocian Philosopher of the Pythagorean School, $1^{\text {st }}$ century AD

Every country on Earth has strong cultural influences from the dominant religious practices of the people. In India, that religion is Hindu. The Hindu population accounts for $83.2 \%$ of Indians, Muslims are $11 \%$, Sikhs and Christians are at $2 \%$ each, and the Jains and Buddhists are each less than one percent. (Budhwar 2001) Ninety-five percent of the Indian Business Community is made up of three Hindu groups, Sindhis, Marwaris, and Gujratis. (executiveplanet.com 2001) Sikhs and Christians do exist in the business community somewhat but it is rare to find a Muslim in the legitimate business community. (executiveplanet.com 2001) India does not have an official religion, yet it is a very spiritual country observing many religious holidays. (Budhwar 2001) The Sindhis, Marwaris and Gujratis are further subdivided into lots of castes and the dietary habits of each differ significantly. (executiveplanet.com 2001) This makes a difference when attempting to entertain. Since the cow is a sacred animal in Hindu, there won't be beef served, or appreciated, in most situations. (Budhwar 2001) The caste system is one of the most important influences in Indian society and inequalities between the castes are the accepted standard possibly overriding the law.

The economic (rich vs. poor) situation in India is important to understand when trying to gain an understanding of the Indian way of life. The country is loaded in extremes where the richest and the poorest exist near each other, with no middle ground. This is most obvious in cities where fine hotels insulate the traveler from India's Achilles heel, the poor. Most cities in India do have very fine hotels. Luxury hotels charge international rates, $\$ 150-\$ 250$, while bargain priced Indian hotels charge somewhere in the neighborhood of $\$ 10$ per night. The best bet - a reason being food that is served - for a business traveler is to stay in a five-star hotel or one that is right under that. (Matthew 2002). Sometimes a hotel that is not quite a five-star is just fine and may be priced at a third of the five star hotels. 
A common concern about going to India for business is how to behave around the women there. If a woman is walking alone, it is not wise to speak to her. The best bet in terms of greeting most Indians - especially women - is to fold palms together while speaking the word "namaste" in a soft tone. (Budhwar 2001; Matthew 2002) Even if the woman is more Western than traditional, it is still the best option and she'll appreciate it.

While this extreme difference in the treatment of sexes may catch a Westerner off-guard, the treatment of women is actually one of deep respect - a glorification of her differences. Yet obedience is still required, more so in less urban areas. To understand why women have such special treatment in India it important to look at Hinduism, the dominant religion. In Hindu mythology the earth is seen as Mother Earth. (Matthew 2002) The representative gender, the woman, must be patient and invite stillness despite the arrogance of mankind, dressing and acting the part of the peace giver. (Matthew 2002) Even though many argue that a sari reveals much more than western clothing, from the Indian cultural position a lady holds the admiration and respect of people when certain signs of womanhood are concealed. Women in business today have a variety of clothing choices from the "salawar-kameez," suits, shirts, and sometimes trousers. Very modern women could be seen in skirts, blouses or even T-shirts.

While family ties in India are obviously strong, family ties in business are the most obvious when conducting business in the country. Families in many instances, run businesses. In businesses run by families, there is a definite distrust of people outside the family. The head of the family has all of the information and may not share it with other members of the family. This leaves the control with the family head, and work may not be able to be accomplished without the head present. (executiveplanet.com 2001)

\section{What you must know to do business in India}

\section{In the Workplace}

The dynamics within the office structure are different from that of the West. Understanding the corporate culture in India is important for dealing with the big picture of Indian business. The caste system, one's lot in life, the unquestioning of authority, and the reluctance to accept responsibility all play a part in office dynamics. Things also move much slower in India compared to the west, with a value on visiting as well as production.

1. Each employee plays a role in the organization; often the role is as important as the actual work the person may perform.

2. In some offices, employees may rise each time the boss enters the room to acknowledge respect.

3. Employees do as they're told even if they know the boss is wrong, they won't argue.

4. The boss makes all of the decisions and accepts all of the responsibility. Consequently, you'll often find that subordinates are reluctant to accept responsibility.

5. Because so many pressures are placed on the boss, qualified Indian employees often do not seek such positions of leadership.

6. Success and failure are frequently attributed to environmental factors.

7. Whenever you are convinced that you are right, insist that whoever objects accepts in writing the full responsibility for the consequences of not following your instructions. Staff members are usually so reluctant to accept responsibility that making this demand usually ensures that your wishes will be respected.

8. It is important to insist that employees write instructions down or for you to distribute written instructions, so that no one can later deny being informed of them. Create a "paper trail" by circulating reports and memos, even to people not directly affected, so that staff members can't claim that you didn't inform them. Complaints, requests, and decisions of any kind should be given in writing.

9. A business traveler who is a boss will be forgiven most lapses in etiquette. But even the slightest altercation, such as shoving or grabbing someone by his or her shirt, is unacceptable. Lose control and you will lose authority of any kind. It is in your best interest to mask any hostile feeling with a smile. 


\section{Appointments}

A precursor to making deals is setting and keeping appointments. Oftentimes, to get to the deal, the initial appointments must go well. There are some differences in Indian appointments and Western appointments. No business comes before the importance of family duties so appointments are set with a rather loose hold on an actual commitment.

1. Indians are not necessarily punctual, although they appreciate it in you.

2. Keep your schedule flexible for last minute schedule changes.

3. Request appointments by letter about two months before arriving in India.

4. Early morning appointments are usually not favored. Aim for meeting between 11 am and 4 PM.

5. General business hours are from 9:30 am to $5 \mathrm{PM}$, in the private sector. Lunch is usually between 1 PM and 2 PM.

6. Be aware that India has many religious holidays that may vary from year to year and region to region. It is wise to contact the Indian Tourist Office, Consulate or Embassy before scheduling a visit to India.

7. Because it is the man's responsibility as head of the household to marry children off, perform birth, death, and other ritual ceremonies, and care for aged parents and other dependant relatives, rescheduling of appointments are a necessary part of doing business in India.

\section{Conversation}

The Indian way of socializing is slightly different from the West. There is much more value put on conversation and developing a personal relationship in business management. (Budhwar 2001) Because of this "way" of doing things, a visiting westerner that is solely focused on the business at hand would be well advised to relax and lay the foundation for a personal relationship before getting to the business issues. Establishing a relationship by general conversation is vital. It is not "all business" in India.

1. Talking about your friends and family is an important part of establishing a relationship with those involved in the negotiating process

2. Conversation is considered an "art form" here; people will put a lot of time and effort into a discussion. This does not mean, however, that you should feel the need to "bare your soul."

3. Indians tend to be enthusiastic about discussing politics and religion. They enjoy opinionated conversations and don't necessarily want to hear only bland pleasantries from a foreign guest. Nevertheless, refrain from tackling these controversial subjects unless you are well informed.

4. As long as you know what you are talking about, you can air dissenting opinions freely. Otherwise, it will be in your best interests to remain silent, especially if the subject is India.

5. Welcome topics of conversation: Indian traditions, foreign countries, other people, families, cricket, politics (if you know what you are talking about), religion (if you know what you are talking about).

6. Topics to avoid: Personal matters, India's military spending, poverty in India, and the significant amount of foreign aid India receives.

Deals

The art of deal making is a skillful craft wherever it is being done. The idea of careful negotiating in a country where even the smallest gaff could be misunderstood is daunting. Entering the deal making process armed with some knowledge and understanding of the country is highly beneficial. Because India has so many cultural differences than in the West, it is important to know what is acceptable. Indians have been dealing all of their lives so it is not wise to underestimate their negotiating skills. In India it's all negotiable so they've had lots of practice. Because they are so skilled in the art of dealing they are much more practiced in being patient while waiting out a better deal.

Always present your business card. Your own language is fine.

1. An Indian intermediary is advisable. 
2. In India, "outside" information and new concepts will be accepted only if they do not contradict prevailing religious beliefs and social structures.

3. Indians tend to think associatively, largely because the country's educational system places a heavy emphasis on rote learning. Indian businesspeople with a higher education, however, are often more abstract, analytical thinkers.

4. In Indian business culture, perceptions of the truth tend to be guided by feelings; a strong faith in religious ideologies is also common.

5. The caste system remains one of the most important influences in Indian society.

6. The head of the family has the final say.

7. Deal with multiple businesses from different castes and you will get more realistic prices in bargaining.

8. Although technically there is equality under the law, inequality between the castes is an accepted reality of Indian life.

9. Because of the strong coherent, social structure there is little anxiety about life because one knows and accepts one's place in society and the workplace.

10. The hierarchical nature of Indian society demands that the boss be recognized as the highest individual in authority.

11. Interpersonal skills such as the ability to form friendships are sometimes considered more important than professional competence and experience. Nevertheless, there is a deep respect in this culture for university degrees.

12. If you are the boss, it's often your presence that's important, so that the negotiations can take place at the top level. Because of the rigid hierarchy in Indian business culture, a subordinate will be able to meet only with a subordinate. Once you have gained access to the necessary senior contact, however, the tow of you may need only to exchange pleasantries while your assistants concern themselves with the details. At this stage, allow your Indian counterpart do the talking.

13. Business in India is highly personal. It is also conducted at a much more leisurely pace than in the States.

14. In Indian culture, any final decision must be in accordance with the family, group, and social structure.

15. Expect Indian negotiators to be shrewd at the bargaining table.

16. Talking about your friends and family is an important part of establishing a relationship with those involved in the negotiating process.

17. Although it's necessary to obtain good legal and tax advice before proceeding with negotiations, you will have to be flexible and not appear too "legalistic" during negotiations.

18. Delays are inevitable and must be expected, particularly when dealing with government bureaucracy. The Indian government is notorious for moving at a slow pace, and communication within the country is often a challenge. You will have to be patient and set aside any unrealistic expectations regarding deadlines and efficiency.

19. There are some foreign women in responsible positions working in India.

20. In Indian business culture, any final decision must be in accordance with the family, group, and social structure.

21. You will have to be prepared to offer competitive technology packages with close technical follow-up, if your business deals with these concerns. The technical assistance you are willing to provide and how effectively you can train your client's employees will be key considerations in the decision. 
Dress

Of all of the subjects a business traveler would be well advised to educate himself on, dress is probably the most noticeable. Many, if not most, of the codes of standard dress for the west are extremely different from India. With a bit of understanding, however, there should be no problem fitting in. Certainly, as in all issues when dealing with such a culturally different society, an open mind is imperative. Generally, Indians follow the dress codes of their particular region, but in terms of work attire men wear a shirt and trousers, and women wear "Salwar-Kameez" saree. (Budhwar 2001)

1. Men should wear a suit and tie, although the jacket may be removed during the summer.

2. Wearing leather (including items such as belts and purses) may be considered offensive, particularly in temples. Hindus revere cows and do not use leather products.

3. Businesswomen should wear conservative dresses or pantsuits.

4. Dresses should not reveal too much of the legs. Pants for women are also acceptable. On more formal occasions, however, if you decided to wear pants, they will have to be "dressy."

5. Indian women often wear a sari to special events; Western women can also wear saris. If you are considering wearing a sari, be aware that it requires practice to walk in one naturally and with confidence. Also, there is a belief among some Indians that saris often do not look flattering on Western women.

6. If you are a woman and decide to wear a sari, make sure that it is one appropriate for the occasion. And never boast that your sari purchase was a "bargain."

7. If you have Indian servants during your stay, they will probably invite you to weddings, naming ceremonies, and related events. For a Western female guest, it is appropriate to wear a sari on these occasions. Your servant hosts will interpret it as a gesture of good will and equality if you make the effort to wear an Indian costume.

8. Another common Indian costume that is perhaps a better option for Western women is the "Punjabi suit." It consists of loose pants and a long blouse. They are usually sold as a set, and are available in a wide variety of styles. You can also have them custom made.

9. For men, most formal events in hot temperatures require a "safari suit," which consists of a short-sleeved shirt-jacket and matching pants.

10. In the winter, suits and ties are appropriate.

11. In Bombay, during the monsoon, a shirt and tie is acceptable.

12. For casual wear, short-sleeved shirts and long pants are preferred for men.

13. Shorts are acceptable for men only when jogging. Women who jog should wear track pants.

\section{Titles}

Getting titles right is impressive. If an Indian businessman were to visit the West and got everything right except proper titles, his credibility would be notched down significantly. It is fair to say that the same standard holds in India.

1. There is a reverence for titles in India. Whenever you can, use professional titles such as "Professor" and "Doctor."

2. For those without professional titles, use courtesy titles such as "Mr.", "Mrs.", or "Miss." Wait to be invited before addressing someone by his or her first name. First names are usually reserved for close friends.

3. A person's age, university degree(s), caste, and profession determines status. Moreover, employment in government service is considered far more prestigious than private business.

\section{Public behavior}

Knowing how to behave in a public setting might not determine the make or break of a deal, but it will certainly make a visit it India much more pleasant, and trouble-free. Young people touch the feet of the elderly as a 
SocioEconomic Challenges, Volume 3, Issue 2, 2019

ISSN (print) - 2520-6621, ISSN (online) - 2520-6214

sign of respect. Men may hug each other, yet a husband and wife don't touch each other in public and pointing is considered impolite. Although you'll observe abundant sexual symbols in Indian society, this does not mean that public intimacy is tolerated.

1. Never try to talk to a woman who is walking alone.

2. Indians of all ethnic groups disapprove of public displays of affection between people of the opposite sex. Refrain from greeting people with hugs or kisses.

3. The majority of Indians are Hindu. Most Hindus avoid public contact between men and women. Only Westernized Hindus will shake hands with the opposite sex.

4. A minority of Indians are Muslim. Traditionally, there is no physical contact between men and women. Moreover, if a woman touches a religious Muslim male, he must ritually cleanse himself before he prays again. Consequently, women should not offer to shake hands with Muslim men (nor should men offer to shake hands with Muslim women). If a westernized Indian, however, offers to shake hands, you should do so.

5. Other Indian religious groups, such as Sikhs and Christians, will also avoid public contact between the sexes.

6. In large cities, men and very Westernized Indian women will offer to shake hands with foreign men and sometimes with foreign women. Western women should not, however, initiate handshaking with Indian men.

7. The traditional Indian greeting is the "namaste." To perform the "namaste", hold the palms of your hands together (as if praying) below the chin, nod or bow slightly, and say "namaste" (nah-mas-tay). This greeting is useful for foreigners in any circumstance in which a handshake might not be appropriate. Moreover, it's a sensible alternative to a handshake when a Western businesswoman greets an Indian man.

8. The comfortable standing distance for Hindu Indians is about 3 or $3 \frac{1}{2}$ feet apart. This generally varies with the cultures.

9. While travelling in public transportation in India, never keep your purse in your back pocket, and avoid carrying a purse if at all possible.

10. To beckon someone, you hold your hand out, palm downward, and make a scooping motion with the fingers. Beckoning someone with the palm up and wagging one finger, as in the States, will often be perceived as an insult.

11. Standing tall with your hands on your hips - the "arms akimbo" position - will be interpreted as an angry, aggressive posture.

12. Pointing with your finger is considered rude; Indians prefer to point with the chin.

13. Whistling under any circumstance is considered rude and unacceptable.

14. Winking will usually be perceived as either an insult or a sexual proposition.

15. In India, grasping the ears signifies sincerity or repentance. Since ears are considered sacred in India, pulling or boxing another person's ears is a grave insult.

16. Feet are considered unclean, so never point your feet at another person. You will be expected to apologize whenever your shoes or feet touch another person.

17. To tip a taxi driver, simply round up the fair.

18. When making purchases at a store, your change is simply placed in your hand, without explanation of the amount.

19. Keep plenty of loose change on hand, as street merchants and taxi drivers will often claim that they don't have change.

20. Expect a deluge of bicycles, motorcycles, and cars. When crossing the streets, you will have to be exceptionally careful and alert. 
21. Giving money to a beggar will only result in your being pestered by dozens of them. The best policy is to avoid even making eye contact.

22. Beware of charming Indian con men. One common scam occurs during long lineups for train tickets or similar items. For example, a man behind you engages you in friendly small talk. He then suggests that if you give him the money, he can get you a train ticket quickly, through one of his connections. He may insist, in the meantime, that you relax and have a cup of tea while he obtains your ticket. Needless to say, he doesn't return. Consequently, don't be naïve enough to give money to strangers in this or similar situations.

\section{Entertaining}

Entertaining clients are a vital part of doing business anywhere. Business entertaining is a bit of a contradiction due to the formality of business mixed with the informality of socializing. Ultimately a businessperson must seem casual while following all of the proper rules. In India, this is no different. Some of the informal rules to entertaining as well as being entertained, however, are significantly different. When weighing the social factors involved, the Indian diet must be considered. Most citizens are vegetarians but fish and grains are also diet staples for many citizens. Beef and pork are not good food choices in India.

1. Arrive 15 to 30 minutes late, unless it is an official function.

2. Because the evening meal is usually reserved for family, business lunches are preferred.

3. Most business discussions will not even begin until tea is served and there has been some sort of "small talk."

4. When refreshments are served, it is customary to refuse the first offer, but to accept the second or third. To refuse any beverage outright, however, will be perceived as an insult.

5. When declining an invitation, it is better to say "I'll try" or "We'll see" instead of the more direct "No, I can't."

6. Sometimes Indian hosts adorn their guests with a garland of flowers when they arrive. The flowers must be removed immediately as a sign of humility.

7. As a visitor to India, you may find plenty of social invitations, including from minor acquaintances and total strangers.

8. When entering an Indian home, remove your shoes.

9. Since a guest in an Indian home is considered a sort of god, etiquette mistakes will never be brought to the guest's attention.

10. Washing your hands both before and after a meal is essential. Moreover, in Hindu homes, you will also be expected to rinse out your mouth.

11. Eat only with your right hand, as the left hand is considered unclean. You may pass dishes with your left hand.

12. Never offer another person food from your plate (even your spouse.) This is regarded with disgust in Indian culture.

13. Do not thank your hosts after a meal. Saying "thank you" for a meal is considered insulting because a generic 'thanks' is perceived as form of payment. Instead, offer to reciprocate by inviting your host out to dinner. This invitation will signal that you value the relationship you have established with your hosts.

14. A guest bedroom is rare. In most middle-class homes, the bedroom is wherever the bedding is rolled out.

15. When staying in a house with servants, you may give them money as a gift due to the extra work they had due to your stay. Let your host dictate the correct amount, so it does not override the servant's monthly pay.

16. When you are hosting a social event, every guest should be contacted personally by phone, even if you have already sent a printed invitation. Be aware that Indian guests will not always "RSVP" or turn up after insisting that they will be attending. 
17. Some guests bring their own guests; you will have to be accommodating.

18. If guests are late, or come with friends (or aged relatives or strangers picked up of the street), or don't come at all, your warm and gracious manner must not change. You should consider the informality of your Indian guests as a compliment, rather than a sign of bad manners.

19. A buffet is the best way to go since you have no idea that is coming.

20. Lamb, chicken, and fish are the meats eaten by all Indians who are not strict vegetarians.

21. Clearly label each buffet dish so guests can decide what they can eat.

22. Hindus do not eat beef and Muslims do not eat pork. All other meat must be "halal" or ritually slaughtered. Jains do not eat meat, honey, and most vegetables.

23. When hosting a party make sure there are plenty of vegetable selections. Some Indians are strict vegetarians.

24. Islam prohibits drinking and the Sikh religion prohibits drinking and smoking but not everyone is a strict observer of these laws.

25. Indian women of a certain social position are almost as likely to drink and smoke as do the men, but traditional Indian women don't do either.

26. For those who do drink, hard liquors (especially whisky) are the most appreciated. It should be imported whiskey, preferably Black Label.

27. Ask, "What would you like to drink?" instead of "Can I get you a beer?" Sometimes regular drinkers will not partake during certain religious holidays or if there is an older, highly respected relative present.

28. Always have juice and soft drinks available for the non-drinkers.

\section{Gift giving}

If a gift is to be given, it is best to know how to do it. Many acceptable standards in the West could be taken offensively in India. However, it is very common to exchange gifts among friends so knowing the rules are a necessary and recommended part of going to India.

1. Gifts are not opened in the presence of giver. If you receive a wrapped gift, set it aside until the giver leaves.

2. Don't wrap gifts in black or white, which are considered unlucky colors. Instead, use green, red and yellow, since they are considered lucky colors.

3. When invited to an Indian's home for dinner, bring a small gift of chocolates or flowers.

4. If you are staying with a family, feel free to ask them what they would like. Certain very basic, practical items taken for granted in the West are unavailable in India. For example, electronic gadgets, computer disks, bandages, instant soup mix, and knives may be requested. Chocolate, disposable razors, perfumes, toiletries, and household items such as sealable plastic containers can also be welcome gifts.

5. If you are sure that your Indian counterpart drinks alcohol, imported whiskey is usually an appreciated gift. The best policy is to purchase whiskey on the airline or at the duty-free shop, to avoid being burdened with the $27 \%$ tax.

6. If you give money to an Indian, ensure that it is an odd number. Usually adding a single dollar - i.e., $\$ 11$ instead of $\$ 10$, does this.

7. Avoid frangipanis when giving flowers. They are associated with funerals.

8. Muslims believe that dogs are unclean. Images of dogs are also considered unacceptable, so never give toy dogs or gifts with pictures of dogs to Indian Muslims.

9. Observant Hindus do not eat beef or use products that are made from cattle. Consequently, most leather products will be inappropriate gifts. 


\section{Conclusions}

As the Indian middle class steadily grows, so will the success of the country. Their knowledge of English is the key to the West. While the battle to retain talented Indians in India prevails, increased dominance on the globe will see a flow of returning Indians, giving their skills to Mother Country. Their technological stand is increasing with more personal computers and cells phones than ever before. Exports, especially software exports, are on the rise. Home phones, presently a shortcoming in India, has doubled in the last couple of years with increases expected to continue. The service industry is enjoying great success, and the quality of products are seeing vast improvements. While China is growing loudly, India's growth is much more subtle - but not to be underestimated.

The culture in India vastly different than the west, but never unmanageable to the business-minded. The office climate considers the caste system, deep respect for authority, and a lack of responsibility. Setting and keeping appointments have a lighter weight of importance in India than in the West. Conversation tends to be social, even in a business setting, and negotiations in India tend to be much sharper than in the West. The clothing of India is largely Western in the business community, with as much traditional dress. The case of women's dress is very different. The accepted Indian greeting is "namaste" while bowing slightly.

Besides the fact that India's untypical growth can be worth years of analysis, it is important to be prepared for more dealings with the Asian country. Indians historically have a natural ability with numbers and this technological era could have been custom designed for their emergence onto the global stage. This has always been the case but since liberalization over 70 years ago, and the current reform minded government taking seriously the potential in privatization, the door to India's talent is opening. And while India steps up her pace to keep up with the world race, there are some things that will remain distinctly Indian. The cultural practices and values that began more that 4000 years ago and have been refined over the centuries are not things that should be demolished to accommodate a more western style. Indian culture can be respected and learned as a system that has surpassed the ages. Our immediate history has learned from India and our long term history is India.

\section{References}

1. India. Encyclopaedia Brittannica $<$ http://www.brittannica.com/eb/article?eu=121161.

2. India: India Jumps Doing Business Rankings with Sustained Reform Focus. Asia News Monitor; Bangkok, 02 Nov 2017.

3. Krishnan, Aarati, Lokeshwarri, S.K. (2015). Doing business in India is like doing business in 29 countries: Mark Mobius. Businessline; 25 Oct 2015.

4. Budhwar, Pawan (2001). Doing Business in India. Thunderbird International Business Review, 43(4), 549-568.

5. Communicating Cross-Culturally In India. India Business Solutions. Available at: http://stylusinc.com/business/india/communicating.htm.

6. Hilsenrath, Jon E. (2000), "Indian Economy Is Set to Beat China. Asian Wall Street Journal. Available at: http://meadev.nic.in/economy/awsj-27apr.htm.

7. IBEF (2018). Available at: https://www.ibef.org/industry/information-technology-india.aspx.

8. Matthew, Matt (2002) India Business Solutions. Available at: http://stylusinc.com/business/india/cultural_tip1.htm.

9. Modi regime can raise India's 'Doing Business' ranking: World Bank chief', Businessline; 23 July 2014.

10. Roy, S. (2018). The Indian consumer market and its changing dynamics", QRIUS. Available at: https://qrius.com/the-indian-consumer-market-and-its-changing-dynamics.

11. Wikipedia (2018). Available at: https://en.wikipedia.org/wiki/Economy_of_India 